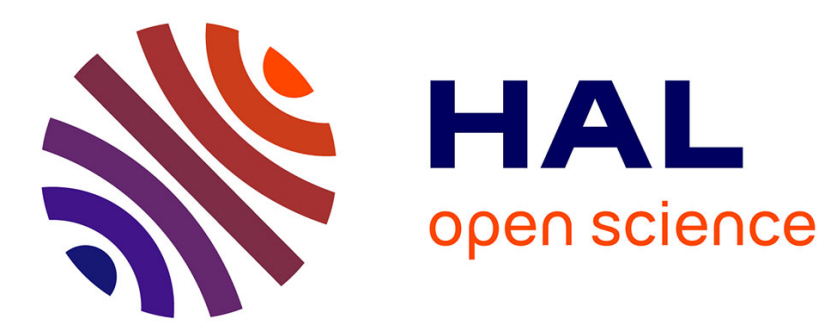

\title{
The strong potential of organic and molecular electrochemistry
}

Olivier Buriez

\section{To cite this version:}

Olivier Buriez. The strong potential of organic and molecular electrochemistry. Current Opinion in Electrochemistry, 2020, pp.A1-A3. 10.1016/j.coelec.2020.100657 . hal-03362348

\section{HAL Id: hal-03362348 \\ https://hal.science/hal-03362348}

Submitted on 6 Oct 2021

HAL is a multi-disciplinary open access archive for the deposit and dissemination of scientific research documents, whether they are published or not. The documents may come from teaching and research institutions in France or abroad, or from public or private research centers.
L'archive ouverte pluridisciplinaire HAL, est destinée au dépôt et à la diffusion de documents scientifiques de niveau recherche, publiés ou non, émanant des établissements d'enseignement et de recherche français ou étrangers, des laboratoires publics ou privés. 


\section{Editorial overview:}

\section{The Strong Potential of Organic and Molecular Electrochemistry}

I cannot begin to write this editorial, devoted to Molecular Electrochemistry, without paying my sincere tribute to Professor Jean-Michel Savéant, who I was fortunate enough to be a student of and who passed away recently. His scientific activity pioneered the development of Molecular Electrochemistry. His impulsion and impact in this field will remain engraved forever. Despite the loss of its most illustrious figure, Molecular Electrochemistry has never been as active and essential as demonstrated by its contribution to some of the major challenges chemical sciences are facing. Obviously, it is not possible to encompass all recent developments and applications of molecular electrochemistry in a single issue. Instead, this section gathers contributions written by experts on current advances in the Organic \& Molecular Electrochemistry field, including important topics such as electrosynthesis and its scale-up, contemporary energy challenges (electrocatalytic conversion of $\mathrm{CO}_{2}$, organic batteries), mechanistic investigations underlying biological redox processes, electrografting of organic films, enantioselective electrochemistry and electrofluorochromism.

Due to the recent revival of electroorganic synthesis, no less than four contributions are devoted to this topic. In the first one, Cheng-Chu Zeng and Sen Liang (Beijing University of Technology) addressed the "Anodic construction of heterocyclic structures". Though the construction of heterocyclic frameworks constitutes one of the most dynamic and attractive branches of organic chemistry, electrochemistry provides a versatile and sustainable approach to prepare such high added value compounds. In this review, a selection of representative examples published very recently are presented and discussed to showcase how to make use of anodic oxidation for the constitution of heterocyclic compounds.

In the second review, Charles H. Devillers, Asmae Bousfiha, and Abdou K. D. Dimé (Université Bourgogne Franche-Comté) describe the "Recent advances in electrochemical meso and $\beta$ functionalization of porphyrins and electrografting of diazonium-porphyrins". This review focuses on the functionalization of porphyrins that have become very attractive with relevant applications in various fields (photovoltaic, sensors, electrocatalysis...). Here again, electrosynthesis appears to be a powerful green alternative to classical chemical synthesis.

The preparation of valuable building blocks is also a central issue in organic synthesis. In their Opinion, Toshio Fuchigami and Shinsuke Inagi (Tokyo Institute of Technology) focused on "Organic electrosynthesis using a fluoride ion mediator". It is particularly shown how fluoride ions can achieve the anodic methoxylation of sulfide derivatives in view of preparing various building blocks. In this review, a methodology to prepare valuable heterocyclic compounds is also described using fluoride ion-mediated anodic intramolecular cyclization through carbon-oxygen bond or carbon-carbon bond formation of organosulfur compounds.

The series of reviews dedicated to organic electrosynthesis could not end without emphasizing the importance of flow cells to scale-up reactions. This is nicely highlighted in the review by Derek Pletcher (University of Southampton) and entitled "Electrolysis cells for laboratory Organic Synthesis". This review clearly summarizes the basic principles, including important parameters that must be taken into account when running electrosynthesis in flow cells. Moreover, it gives a nice overview of the 
latest advances in the flow cell design as well as on their availability. This should convince electrochemists to perform electrosyntheses in flow cells more often.

The contribution of molecular electrochemistry is also of high importance in contemporary energy challenges. Within this context, the electrocatalytic conversion of $\mathrm{CO}_{2}$ is an appealing method for storing energy in the form of carbon-based fuels or for generating value added chemicals. In their Opinion, entitled "Emergence of $\mathrm{CO} 2$ electrolyzers including supported molecular catalysts", Marc Robert, Kristian Torbensen, Benjamin Boudy, Dorian Joulié, and Niklas von Wolff (Université Paris Diderot) shows how the use of supported molecular catalysts in eletrolyzers, instead of solid state precious metal catalysts, appears to be relevant to overcome some limitations such as the catalyst and substrate mass transfer to the electrode, or the catalyst solubility which constrains the choice of electrolyte solution.

Parallel to the electrocatalytic conversion of $\mathrm{CO}_{2}$, the development of all-organic batteries is probably one of the most promising approaches to render the electrochemical energy storage technology green and sustainable. In this context, Tatiana Magdesieva, Vyacheslav V. Sentyurin, and Oleg A. Levitskiy (Lomonosov Moscow State University) provided an account on the "Molecular design of ambipolar redox-active open-shell molecules: principles and implementations" and on "Molecular design of ambipolar redox-active molecules II: Closed-shell systems". The authors highlighted key structural features and provided guidelines for the molecular design of ambipolar redox-active frameworks (open-shell and closed-shell molecules), which are of interest for the fabrication of all-organic "poleless" batteries and semiconductors.

The quest for a better understanding of molecular mechanisms underlying biological redox processes has naturally highlighted the central place of electrochemistry in this field. Thaissa L. Silva, Maria de Lourdes S. G. de Azevedo, Fabricia R. Ferreira, Danyelle Candido Santos, Christian Amatore, and Marília Goulart (Universidade Federal de Alagoas) especially describe the "Quinone-based molecular electrochemistry and their contributions to medicinal chemistry: a look at the present and future". In this review, the authors focused on quinone derivatives which are important molecules leading to a variety of beneficial/hazardous effects in vivo. Nevertheless, obtaining information about the structure-activity relationship only from the molecular electrochemistry approach is not always fully straightforward. Combination of electrochemistry with other analyses appears therefore to be a relevant strategy to rationalize the mechanisms met in the corresponding biological processes.

Eric Labbé and Olivier Buriez (PSL University - Paris) provided an account on "Disclosing the redox metabolism of drugs: the essential role of electrochemistry" in which the electroanalytical characterization of the successive redox and redox-coupled reactions was found effective to unravel more complex mechanisms, especially those related to the reactivity of bio-organometallic drugs. This review highlights the contribution of these different electrochemical strategies to the determination of drug metabolism through representative recent examples.

Another important facet of molecular electrochemistry concerns the surface modification of materials with organic moieties through their electrochemical activation. This topic is nicely highlighted by Jean Pinson and Fetah Podvorica (Universite de Paris) in their review entitled "Surface modification of materials: electrografting of organic films". Nearly 30 years after its discovery, the surface reaction of diazonium salts is still a very active field. This is once again proved in this review which focuses on recent advances made in various key points such as: new materials that have been modified through 
the reduction of diazonium salts, new methods for surface modifications, new strategies to control the structure of organic films, new reactions which extend the scope of diazonium grafting.

Enantioselective electrochemistry to discriminate analytically the enantiomers of chiral molecules is an important issue especially in the biological and pharmaceutical fields. Within this context, Sara Grecchi, Serena Arnaboldi, Simona Rizzo and Patrizia R. Mussini (Università degli Study di Milano) focused their review on "Advanced chiral molecular media for enantioselective electrochemistry and electroanalysis". Chiral molecular media of high local order at the electrochemical interphase (chiral ionic liquids, deep eutectic solvents with chiral components, chiral additives added to achiral high order media) are indeed an interesting alternative approach with respect to electrode surfaces modified with chiral selectors. An overview and a discussion of the enantiodiscrimination results obtained so far in electrochemistry and electroanalysis applications are presented.

The role of electrochemistry in the tuning and monitoring of photoluminescence is essential as asserted by the numerous possible applications notably in materials and biological fields. In his Opinion article, Fabien Miomandre (Ecole Normale Supérieure Paris-Saclay) showed "How molecular electrochemistry may shine light by designing electrofluorochromic compounds". In this review, the focus is made on molecular aspects of this important topic and especially concerns the three most important classes of redox-active luminescent molecules (Dyes, Dyads and Polymers). Some frameworks for the use of these molecules in fundamental studies or devices are also discussed.

In conclusion, whilst this issue is not aimed at providing a comprehensive coverage of all aspects of organic and molecular electrochemistry, it has the ambition of emphasizing the most prominent aspects of this remarkably active field through illustrative examples of its recent developments. 